\title{
Grade Exam Management System Design And Implementation Based on ADO.NET
}

\author{
Cao Shuguo \\ Academic Affairs Office \\ Chongqing University of Education \\ Chongqing, China \\ 400067 caoshuguo@yeah.net
}

\begin{abstract}
The grade examination management program is various, workload is big, and efficiency is low. This paper on the basis of the existing educational system and the provisions of the state on the basis of grade examination system, developed a test management data transfer system based on ADO.NET technology, the heterogeneous data interconnection test process, the full realization of cyber source sharing, improving the efficiency of examination management. Through the introduction of test data of the design has been completed and mature and stable operation of the system, detailed description of the design and implementation, it has good application value.
\end{abstract}

Keywords-ADO.NET; interface; resource sharing; Grade examination

\section{THE PRESENT SITUATION OF GRADE EXAMINATION ORGANIZATION}

As the required discipline for each college students, Computer And Foreign Language Level Test (CAFLLT) [13 ] as required in tests of college students discipline, is required to take for each students during the period of school in at least one time. So for the vast nationality and the significance of the importance for such the test, the test department has the heaviest workload. The whole test is organized and structured by the national or provincial education department unified management, span longer time, from the registration fee, and print documents, has been to participate in the test scores query, and the middle and test set for departments, paper printing, distribution, arrange the examination site, the arrangement of the examination room, organization invigilation, marking, results login, examination paper analysis and a series of the high density [4], program trivial and a neural tight work. Due to the artificial participation, the load of all process is high, the error probability increase greatly and the whole test is timeconsuming and let a person struggling to keep up.

At present, the main grade examination is responsible for the unified by each college educational administration department, at receive superior department examination announcement, educational administration department [5] will allow the students' registration information to be recorded provisions of the registration system, to create all kinds of test data report, approval to obtain the superior department results summary to return to the students' test scores, and entering school own educational administration management system, when students can access [6] to their test scores, the test time has in the past few months. Registration system and educational administration management system, between the basic data can be Shared, but since there is no standardized management interface and cause data to repeated input, waste a lot of manpower, material resources and time, error probability also increase greatly, statistics and because of large amount of data, artificial reason more and form all kinds of, difficult to standards, that is, to the back of the statistical work to bring a lot of hidden trouble.

Along with the network popularization and all kinds of test of the systematic, automation, this kind of prolonged wasted a lot of human, material and financial test should also be put on the reform agenda, i.e., all kinds of grade examination management need to have a unified data transfer system, the use of database standard interface fully realized the existing each system resource [4-6] sharing, make the test management standardized, systematic, programming, and at the same time, improve the efficiency of information processing, quality and accuracy, and make students, schools and test organization party can timely, accurate and efficient query, statistics and jurisdiction in revising the relevant test information. Therefore, the use of database interface, the integration of the system and the existing educational administration system, Shared data resources, improve work efficiency, improve the quality of work, to develop a system of management between conversion system is imminent

\section{THE BRIEF INTRODUCTION TO ADO.NET}

It is a kind of data access model, the kernel is using XML, has the scalability, Web no state characteristics. Although ADO.NET is the next generation of ADO, but ADO.NET with ADO difference is very big. ADO [7] is based on connection, and ADO.NET depends on short, based on XML news and data interaction, which makes the based on Internet application is concerned, the efficiency of ADO.NET is much higher. At the same time, and database interaction, ADO database for locking, and long time to connect to the database, and ADO.NET don't need. ADO.NET used offline database (using DataSet object), this makes it has better scalability.

For different.net data provider, ADO.NET using different Connection object connected to the database, so as to realize 
ADO.NET and database communication. The Connection object for our shield the specific implementation details, and provides a unified realization method. Connection objects have SqlConnection, OleDbConnection, OdbcConnection and OracleConnection four types. Among them, the SqlConnection object is used as a class connection SQL Server database; OracleConnection object is used as a class connecting Oracle database; OleDbConnection object of is used as a class connection support OLEDB database, such as EXCEL, Access; And OdbcConnection object is used as a of a class connection any support ODBC database. ADO.NET and database of all communication is finally all through the Connection object to finish. In the ADO.NET model, use different Connection object need to import different namespace. SqlConnection namespace for System. SqlClient; Data. OleDbConnection namespace for System. Data. The OleDb; OdbcConnection namespace for System. Data. Odbc; OracleConnection namespace for System. Data. OracleClinet, at the same time must also import System. Data namespace.

\section{THE ANALYZE OF THE REQUIREMENTS FOR THE SYSTEM}

Grade examination conversion system, using ADO.NET [8] technology, is an example of the interface of college educational administration system of existing resources sharing, directly into the system, to realize the resource sharing in the premise, complete level test registration and other major work, so the system should have the following function module:

\section{A. The 'Online application' Function module}

In this module inside, system directly call the school educational administration system middle school students basic information, simplify the information recorded, students only need to choose to enter oneself for an examination subjects and affirm can complete registration procedures. Namely, the student reference basic information directly with the help of educational administration system to accomplish. Students at ordinary times according to the habit of achievement inquires, login educational administration system, can see the "rank test registration notice", through the notice of the link interface, open the students' personal registration page, easy steps complete trivial registration procedures. These function modules directly use of the present educational administration system has repeatedly check students basic data, simplify the registration procedures, let the students no longer repeated input id number and other important information and avoid the input error, and the operation is simple, convenient, more simplified the related staff work. Students are required to finish the online grade examination, can through this module to check their registration information, and can be within the prescribed time revising the relevant information, such as cancellation, modify, enter oneself for an examination subjects, grade, etc. Students may at any time through the module tracking test information, such as the test time, place, and after the test results.

\section{B. The 'Information Setting' Function Module}

In this module inside, mainly by the system administrators set up the test information, such as add test subjects (including level, language, etc., the same below), the test time, charge standard, the start-stop time information, and activation level test registration notice, and also can remove the historical data.

\section{The 'Application Management' Function Module}

The system administrator can check all the subjects to enter oneself for an examination through the module, and also can according to the school (department), professional, class print enter oneself for an examination list, issued to the school (department) check registration information and complete charge. System directly generated report not only convenient management personnel directly statistical correlation data, and unified batch check and pay cost also greatly improve the management team work efficiency, but also save the student queue capture time.

\section{The 'Information Transformation' Function Module}

The student to complete the registration and pay cost later, management personnel through this function batch export to enter oneself for an examination the students list, by implementing the corresponding code and database interface will be previous information read in provisions "grade examination registration system", and at the same time, the educational administration system of teachers, the classroom, and other information also through the code read in regulation system, and in the regulation system complete admission ticket number, the information such as the examination room arrangement

\section{E. The 'Grade Transformation' Function Module}

This function is mainly used for receiving the superior department returning student score data, and introduction to the educational administration system. The superior department return performance data, are generally EXCEL form, will EXCEL form data, according to the student id key read in corresponding students semester grades, students can login educational administration system to their inquires test scores.

\section{F. The 'Report Management' Function Module}

This function module is mainly provides some commonly used statistical statements, such as the subject test percent of pass, each class, professional percent of pass, and other functions, and can also generate bolo students according to the class list

\section{SYSTEM DESIGN}

Work to do his work well, must first sharpen his device. To be a good data transfer system, the good tool selection is indispensable. According to the demand analysis determined system function, considering the current college students generally breakthrough tens of thousands of people, and each 
reference number in the thousands of people are the actual situation, the system design is as follows:

\section{A. System operation Mode}

Due to the client are many, access Server concurrency is bigger, so the system is running the safety performance of high B/S mode, namely the Browser/Server (Browser/Server) [9] model that the biggest advantage is the network client without any limitation. Namely the browser in hypertext forms to Web server puts forward the requirements of access database, Web server receives the client request, will be the request into SQL grammar, and to the database server, database server get request, verify its legitimacy, and data processing, and then will process after the results back to the Web server, Web server will get all the results can be transformed into and become an HTML document form, transmitted to the client browser to friendly Web page display form. Due to the need to query the database, involving dynamic web programming, therefore, the system USES the technology powerful, scalability and customizable sex are very good based on server ASP.NET as a software development tools. This model system centralized deployment in the server, so the data for centralized storage management more real-time and security, unity and integrity.

\section{B. System Client}

Relative to the C/S structure "fat" client, which are needed in the end users on a computer installed on the operation of the corresponding software, and $\mathrm{B} / \mathrm{S}$ structure is to belong to a typical "thin" client, B/S structure of the system does not need to install the client software, the client only need to run browser software open the corresponding dynamic link pages can. Namely, the need for the thousands of the student, as long as the network terminal have browser can easily finish the work. Based on B/S structure model of the client is very simple, can choose different technology and architecture, also facilitate between heterogeneous system more convenient integration and integration, and system scalability is very good.

\section{System Server}

Because the system adopts $\mathrm{B} / \mathrm{S}$ mode operation, the system required for the operation of all software is installed in the server, most or all of the major business logic in the server. For high concurrent (several thousand to tens of thousands of concurrent users above) application, also facilitate use server cluster. System development once in place, can realize different personnel, from different places, with different access methods (such as LAN, WAN, Internet/Intranet, etc.) access and manipulate a common database; Can effectively protect data platform and management access, server database is also very safe. Therefore, the system upgrade or maintenance also need to update the server software can, greatly simplifying the client computer load, reduce the system maintenance and upgrade cost and workload, lower overall cost.

\section{System Data Interface}

Due to the large amount of data, concurrent access to more, so this system to backend database request is higher. That is the database must have good performance and reliability, access speed will is opposite taller, this system database using SQL Server 2000 as a backend database. Although the SQL Server also support OLEDB [10] data interface, but in ADO.NET, provides SqlConnection class and SQL Server database data communication, but OleDbConnection class have no way to make use of the SQL Server database of some new characteristics, therefore, not recommended OleDbConnection class to access SQL Server database, and only used for the visit to EXCELUsing the Template

\section{SYSTEM IMPLEMENTATION}

\section{A. The Database System Design}

In the school educational administration system, there have been quite a number of data, such as students' basic information, and class information and professional information, school (department) information and so on, to add some auxiliary for data transfer in the middle of the table, can easily realize the data conversion.

Existing database table and the corresponding field as follows:

Students' basic information table: Jw_xsxx (student id, name, gender, id number, class number, password, authority...)

The class information table: Jw_bj (class number, professional number, name of the class, grade, at the campus...)

Professional information table: Jw_zy (professional number, professional name, department number, level...)

School (department) information table: Jw_yx (departments' number, department name...)

Students score: Jw_xscj (student id, semester, course code, the result......)

Because most data ready, to reduce the data redundancy, the system needs additional tables and fields are as follows:

Enter oneself for an examination subjects table:

Bm_km (course code, course name, start time and end time, cost standard...)

The list: Bm_md (student id, course code, semester)

\section{B. System Interface}

The whole system, mainly divided into two parts, one is the students to use the online application interface, and another part is for the dean's office is responsible for grade examination management teacher use management interface. In the student online application interface, students through the educational administration inquiry system of notification address links, into the system of "grade examination online registration" [6] function, as shown in figure 1 shows, the 
vast number of students information also automatically read to the registration system, students only need to recognize the relevant information and correct, then the subject from the drop-down list on the right side (figure 2) selection for the registration of subjects, click on the "Register" button register.

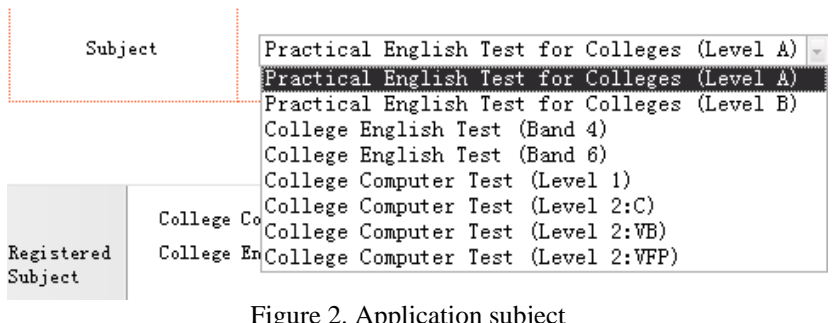

In the provision of the time, students can also click the "अ Cancel" icon behind "Registered Subject" to cancel the course, in this function inside, students can also see the timely enter oneself for an examination should pay the relevant expenses.

In the management interface (figure. 3), the administrator teacher can easily to add, delete or edit the exam course, at the same time can also check the students' information, and the registration data and some other basic data (eg.the classroom, teachers' information, etc.) derived generation intermediate EXCEL documents, etc.

\section{Key codes}

Because the original educational administration management system database is to use MS SQL [8] Server database, and the provisions of the grade examination management system needs to use the standard EXCEL file as reported data, therefore, in the system design inside, use ASP.Net through ADO.NET SqlConnection class access SQL Server database, read related data to create standard EXCEL documents become the key to all the work, its core code is as follows:

<\%@ Import Namespace="System.Data"\%>

$<\% @$ Import Namespace="System.Data.SqlClient"\%>

$<\% @$ Import Namespace="System.Data.OleDb" \%>

Dim Conn as SqlConnection

Dim SourceIP As String

SourceIP="10.3.10.1"

Conn=New SqlConnection ("Server="\& SourceIP

\&";UID=sa;PWD=sa;Database=jwdb")

Dim strConn As OleDbConnection

strConn

OleDbConnection("Provider=Microsoft.Jet.OLEDB.4.0;

Data Source $=\mathrm{C}$ :/www/input_excel.xls;Extended

Properties=Excel 8.0; ")

......

$\%>$
In the above code, the back part using the bottom OLEDB interface, the purpose is to ensure that read access to the database data, even if the server system not installed EXCEL software, ASP.NET application also support import and export standard EXCEL format file. Through the SqlConnection and OleDbConnection object connection, the following code inside can use the standard SQL statement to realize all kinds of add, delete, modify, and inquires the operation, etc.

Generate standard for data exchange EXCEL document before, we need to advance in accordance with the prescribed level examination system into data format to EXCEL file Settings, and will EXCEL file save as HTML document type. Will EXCEL document save as HTML file type, the default character set is GB - 2312, to ensure that the output file there is no messy code appear, and specify the output filename, we need to control in the code inside:

$<\%$

Response.Charset="GB2312"

Response.ContentEncoding

System.Text.Encoding.GetEncoding("GB2312")

Response.ContentType ="application/vnd.ms-excel"

response.AddHeader("content-disposition","inline:

filename=output.xls")

$\%>$

$<$ html xmlns:o="urn:schemas-microsoft-

com:office:office"

xmlns: $x=$ "urn:schemas-microsoft-com:office:excel"

xmlns="http://www.w3.org/TR/REC-html40">

$<$ head $>$

$<$ meta http-equiv=Content-Type content="text/html;

charset $=$ gb2312">

$<$ meta name=ProgId content=Excel.Sheet $>$

$<$ meta name $=$ Generator content="Microsoft Excel 12" $>$ ......

\section{CONCLUSION}

The Grade Exam Management System proposed in this paper has advantages such as simple in client requirement, which need the necessary basic Network configuration, with the vast majority of installation and maintenance work to be dealt with the server. The System installation and maintenance is convenience, high in safety with proper applicability. Due to the ADO.NET mature technology, resource sharing realization is easy, which can fully use the existing educational administration system resources, therefore greatly simplify the data entry work and the work flow, And at the same time, completed the decrease of the intermediate links the probability of error. All the work has greatly improved the work efficiency of college educational administration department, with actual verification, the system is proved to be acceptable. 
[1] QianYong. College English level test management information system design and implementation [J]. Computer application and software, 2010 (10)

[2] ZhouLiLi. Based on B/S structure of grade examination management system [J]. Computer engineering, 2005 (7).

[3] JianYouGuang, QinGuangQuan. National computer rank examination study [J]. Continue to education research, 2008 (09)

[4] YangZhiGong, ZouYunLan. Computer grade examination system discussed some technology [J]. Computer era, 2008 (8)

[5] ChenXian. University grade examination management [J].journal of education review, 2008 (01)

[6] Bin Chen, and Nong Xiao, "SCS: A VM-Based Approach to Achieve High Scalable and Available Server Environment", JCIT, Vol. 2, No. 1, pp. pp.16 pp.27, 2007.
[7] Wu CHEN, Yan CHANG, Yunfeng LI, "The Application of Enterprise Group Management \&Control Mode in The Energy Company: The Distinctive Management \& Control Mode in State Grid Corporation of China", JDCTA, Vol. 7, No. 1, pp. 66 73, 2010.

[8] Fen-Hui Lin, Hsing-Ya Chang, "The Influences of Transaction and Partnership Characteristics on Inter-organization System Integration in Manufacturer-Supplier Dyads", IJEI, Vol. 3, No. 1, pp. $24 \sim 33$, 2012.

[9] Xiaodong Zhou, "Model for Evaluating the Benefit of Enterprises in The Background of Market Economy with Uncertain Information", JDCTA, Vol. 6, No. 23, pp. 691 697, 2012.

[10] Zhang Wei, Zhang Qingpu, Shan Wei, Wang Lei, "Role Of Social Media In Knowledge Management During Natural Disaster Management", AISS, Vol. 4, No. 4, pp. 284 292, 2012

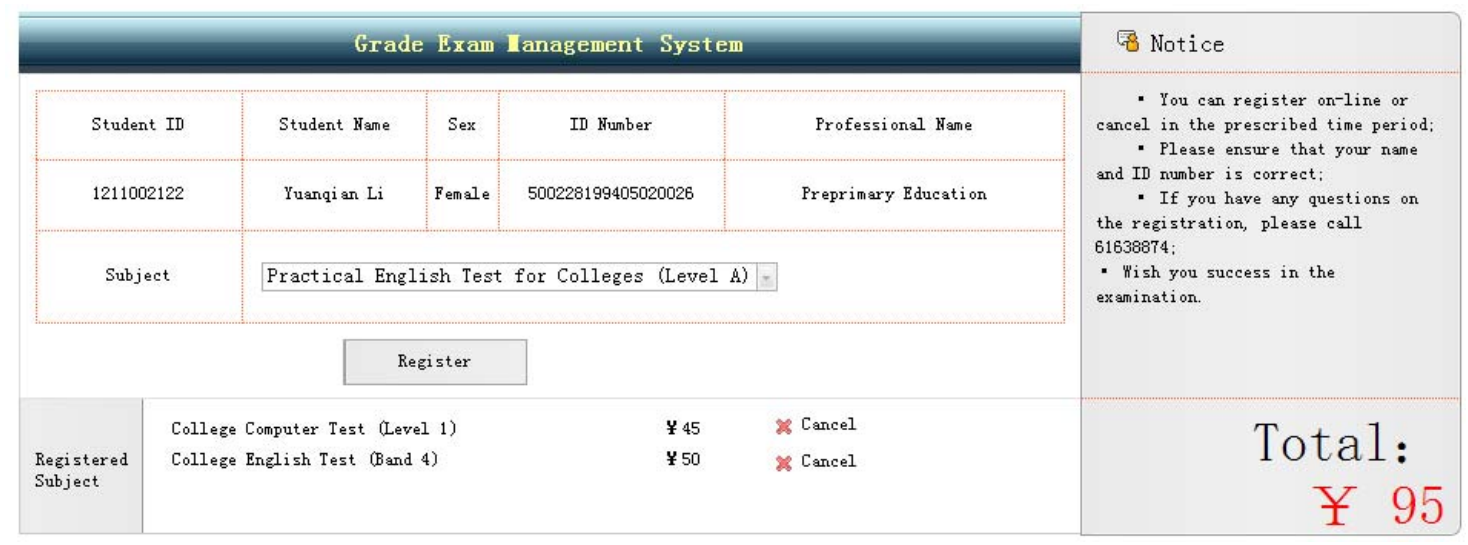

Figure 1. Grade examination online application interface

\begin{tabular}{|c|c|c|c|c|c|c|c|}
\hline \multirow{2}{*}{$\begin{array}{l}\text { 10 Adnin marr meru } \\
\text { Information Set }\end{array}$} & \multicolumn{3}{|c|}{ Active user : admin } & \multicolumn{4}{|c|}{ - Wel come to use Grade Exam Management System (GBMS) } \\
\hline & \multicolumn{3}{|c|}{ Dinformation Set } & \multicolumn{2}{|c|}{ Delect a } & 1 + Add \# Del & Edit \\
\hline \multirow{3}{*}{$\begin{array}{l}8 . \\
\text { Course }\end{array}$} & $\square \quad \begin{array}{c}\text { Course } \\
\text { Code }\end{array}$ & Course Hame & Start Time & Close Time & $\begin{array}{c}\text { Cost } \\
\text { Standard }\end{array}$ & $\begin{array}{c}\text { Preferenti al for } \\
\text { Repeated }\end{array}$ & $\begin{array}{c}\text { Basic } \\
\text { Operation }\end{array}$ \\
\hline & $\square \mathrm{Djks001} P \mathrm{Pr}$ & tical English Test for Colleges (Level A) & 2012-09-01 & 2012-09-24 & 40 & & Del | Edit \\
\hline & $\square$ Djks002 $\mathrm{P}_{2}$ & tical English Test for Colleges (Level B) & $2012-09-01$ & $2012-09-24$ & 40 & & Del | Edit \\
\hline \multirow{6}{*}{ [0] Hotice } & $\square$ Djks003 & College English Test (Band 4) & 2012-09-01 & $2012-09-24$ & 50 & 6 & Del | Edit \\
\hline & $\square$ Djks004 & College English Test (Band 6) & 2012-09-01 & $2012-09-24$ & 50 & 6 & Del | Edit \\
\hline & $\square$ Djks005 & College Computer Test (Level 1) & 2012-09-01 & $2012-09-24$ & 45 & & Del | Edit \\
\hline & $\square$ Djks006 & College Computer Test (Level 2:C) & 2012-09-01 & $2012-09-24$ & 50 & & Del | Edit \\
\hline & $\square$ Djks007 & College Computer Test (Level 2:YB) & 2012-09-01 & $2012-09-24$ & 50 & & Del | Edit \\
\hline & $\square$ Djks008 & College Computer Test (Level 2:VFP) & 2012-09-01 & $2012-09-24$ & 50 & & Del | Edit \\
\hline App. Management & \multirow{5}{*}{\multicolumn{3}{|c|}{ Total: 8 Records, Page $1 / 1$}} & \multirow[t]{5}{*}{ (1) } & \multirow[t]{5}{*}{ ख } & \multirow[t]{5}{*}{ 凶 } & $\mathrm{Page}_{\square}$ (C) \\
\hline Info. Transform & & & & & & & \\
\hline Grade Transform & & & & & & & \\
\hline Report & & & & & & & \\
\hline Desizn:CQUE & & & & & & & \\
\hline
\end{tabular}

Figure 3. The management interface 